\title{
A FORMAÇÃO DO ENFERMEIRO: UMA APROXIMAÇÃO À RECENTE P RODUÇÃO CIENTÍFICA (2001-2005)
}

\author{
TRAINING IN NURSING: A CLOSER LOOK AT THE RECENT SCIENTIFIC \\ PRODUCTION (2001-2005)
}

Otília Maria Lúcia Barbosa Seiffert 1

Resumo Este artigo tem como objetivo apresentar resultados preliminares da produção científica sobre a formação profissional do enfermeiro d i v u l gada em periódicos científicos brasileiros. As fontes deste estudo são a Revista Latino-Americana de Enfermagem e a Revista Mineira de Enfermagem (Reme), escolhidas entre 129 periódicos brasileiros na área da enfermagem, cujos textos completos estão disponibilizadoson-line no Portal de Periódicos da Coordenação de Aperfeiçoa mento de Pessoal de Nível Superior (Capes). Entre editoriais, artigos de pesquisa, artigos originais, revisões bibliográficas, relatos de experiências, notas/informativos, foram selecionados 36 textos da Revista Latino-Americana de Enfermagem e 15 da Reme. A análise desse material compreendeu a leitura dos resumos para a identificação do tema central - formação do enferme iro - e a leitura dos textos completos selecionados, da qual emergiram três núcleos temáticos: fundamentos pedagógicos, ensino de enfermagem e currículo. A análise das produções evidencia uma articulação entre a formação e as recentes políticas públicas para saúde e educação, representando contribuições rele vantes para repensar o perfil profissional do enfer me i ro a ser formado e a proposta curricular desenvolvida nas instituições de ensino de nível superior.

Palavras-chave enfermagem; educação profissional; currículo; produção científica; periódicos científicos.
Abstract This article presents preliminary results of scientific research on training in nursing published in Brazilian scientific journals. The sources for the study were Revista Latino-Americana de Enfermagem and Revista Mineira de Enfermagem (Reme), which were chosen among 129 Brazilian journals on nursing whose complete texts are available on-line at CAPES's [Coordination for the Improve ment of Higher Education Personnel] website. Among editorials, research articles, reviews, case studies and newsletters, 36 texts were selected from Revista Latino-Americana de Enfermagem and 15 from Reme. The analysis of the material included the assessment of the main theme (training in nursing) from the abstracts and the reading of the complete texts, which were, thus, classified into three major th e mes: pedagogical rationale, teaching in nursing and nu rsing school programs (curriculum). The analysis of the texts revealed a connection between training in nursing and recent public policies for health and education, which, in turn, contributed to the process of rethinking both the professional profile of the nurse and the nursing curricula of higher education institutions.

Key wo rds nursing; professional education; curriculum; scientific production; scientific journals. 
"O homem não pode ser compreendido fora de suas relações com o mundo, de vez que é um 'ser situado', um ser do trabalho e da transformação do mundo. (...) Nestas relações com o mundo, através de sua ação sobre ele, o homem se encontra marcado pelos resultados de sua própria ação. Atuando, transforma, cria uma realidade que, por sua vez, envolvendo-o, condiciona sua forma de atuar. Não há, portanto, como dicotomizar o homem do mundo, pois que não existe um sem o outro" (Freire, 1979, p. 28).

\section{Introdução}

Este artigo tem como objetivo ap resentar alguns resultados preliminares de uma investigação mais ampla relativaà produção científica sobre educação em saúde. Voltamos nosso olhar à formação do enfermeiro, procurando conhecer a produção científica veiculada em periódicos brasileiros da área de enfermagem.

A construção deste estudo foi orientada pela premissa de que os artigos científicos representam um dos mais importantes meios de comunicação entre pesquisadores, educadores e profissionais da saúde. Neles, encontramos pesquisas não somente sobre os progressos científicos em áreas especializadas, mas também debates e estudos sobre a formação de profissionais das ciências da saúde. Contudo, cabe reconhecer que "o fator de impacto das revistas reveste-se em um útil, porém não único elemento para entender o progre sso e difusão de nossa produção científica" (Coimbra apud Marziale, 2004).

Nesse sentido, o perc u rso por ambientes de divulgação científica também nos faz reconhecer que:

“(...) a ciência encontra seu lugar social na produção de papers, ou seja, ela se constitui num fazer discursivo-argumentativo que não 'descobre' os fatos científicos (como se eles existissem a priori) pré-existentes [sic] em algum lugar oculto da natureza, mas cujo fazer é constitutivo da própria rotina de produção que os gera. Na ve rdade, está na produção e principalmente na publicação depapers a condição legítima e a atribuição de autoridade da enunciação científica. Em suma: o modo de organização das comunidades científicas mantém uma ligação intrínseca com o modo de funcionamento do discurso científico" (Zamboni, 2001, p. 33).

Considerando desafios inerentes a uma análise dessa natureza, este estudo, em sua fase inicial de desenvolvimento, não tem a intenção de emitir julgamentos sobre os conhecimentos sistematizados pelos autores. Busca, na verdade, verificar as inclinações temáticas da produção científica sobre a formação do enfermeiro, identificando possíveis contribuições para o atendimento de demandas que vêm sendo impostas pelas políticas dos setores de saúde e educação e práticas assistenciais às pessoas no contexto da sociedade brasileira. 
Assim sendo, organizamos este artigo da seguinte maneira: breves apontamentos sobre fatos que sinalizam desdobramentos na configuração do campo da enfermagem e na formação desse profissional; o percurso metodológico que tem possibilitado a ap roximação à produção científica em foco; síntese dos conhecimentos produzidos; e, por último, considerações sobre as contribuições percebidas.

\section{A enfermagem profissional no Brasil: breves apontamentos}

Na atual conjuntura histórica, permeada por cenários complexos e contraditóri os, sobretudo no que diz respeito às transformações do mundo do trabalho, destaca-se a problemática do conhecimento e da formação profissional diante do processo de reestruturação produtivado capitalismo global (Catani, Oliveira e Dourado, 2001).

Com o propósito de redirecionar os processos de formação, conforme apontam Lúcio e Sochaczewski,

\footnotetext{
"Revê-se o seu conteúdo, discute-se sua eficácia e eficiência, reavaliam-se suas relações com outras formas de conhecimento, coloca-se em cheque [sic] seus objetivos. Atores sociais disputam visões e projetos para a formação profissional e negociam-se formas e processos.Enfim, seja do ponto de vista técnico, educacional, político ou econômico, a formação profissional está na agenda da sociedade" (Lúcio e Sochaczewski, 1998, p. 104).
}

No âmbito dessa discussão, inclui-se também o profissional da saúde, cuja preocupação volta-se aos fundamentos que orientaram e orientam o desenvolvimento das ciências da saúde, à formação e às práticas profissionais.

Visando situar a enfermagem no Brasil, entendemos ser necessário destacar alguns fatos de sua história para uma melhor compreensão do percurso da formação dessa categoria profissional.

Após a institucionalização da enfermagem profissional em 1923, com a criação da Escola de Enfermeiras do Departamento Nacional de Saúde Pública (DNSP), atualmente a Escola Ana Nery, vinculada à Universidade Federal do Rio de Janeiro, as mudanças nas orientações legais referentes à profissionalização explicitam as necessidades oriundas do contexto sociopolítico e econômico da nação. Esse processo inicial da enfermagem profissional tem suporte organizativo de um grupo de enfermeiras norte-americanas (Missão Pa rsons), com uma visão de mundo consoante a ética protestante e orientada para a conduta metódica racional (Barreira, Sauthier e Baptista, 2001).

É importante destacar que, nesse período, é constituída a Associação Nacional de Enfermeiras Diplomadas Brasileiras (1926), que, em 1954, pas- 
sa a ser denominada Associação Brasileira de Enfermagem (Aben) (Rodrigues, 2005).

Após 1930, a tendência centralizadora do Estado brasileiro se intensifica, com conseqüentes demandas à ampliação de suas bases sociais, ganhando destaque questões re fe rentes à saúde e educação. Há estreitos vínculos entre economia e saúde, em que se identifica uma política previdenciária, voltada a uma medicina curativa, individual e preocupada com a classe trabalhadora, bem como uma política sanitarista diretamente dirigida a programas gerais de saneamento básico e a campanhas de erradicação de determinadas moléstias, como tuberculose, lepra, febre amarela, febre tifóide, cólera e varíola (Silva, 1989).

A partir de 1949, ano da regulamentação do ensino de enfermagem (lei $\mathrm{n}^{\circ} 775$ ), até 1972, registra-se uma tendência de gradual ap roximação ao modelo biológico, centrado na doença e tendo como principal espaço de atenção o ambiente hospitalar, acompanhando nitidamente o movi mento desenvolvimentista brasileiro e a conseqüente urbanização da população.

A Aben, nesse contexto, exe rce papel importante na configuração da enfermagem brasileira, sendo sua postura reconhecida como 'fundamentalmente conservadora', por manter uma ap roximação irrestrita às políticas oficiais e determinações originárias dos centros decisórios (Rodrigues, 2005).

É oportuno destacar que, na década de 1940, com o surgimento do Estado de bem-estar social em países desenvolvidos, descortina-se a necessidade de colocar em debate a assistência médica, a origem de modelos de atendime nto à saúde (da inclusão dos não doentes no âmbito da ação médica), na perspectiva de favorecer uma prática compromissada dos profissionais da saúde. Ao lado disso, nas décadas de 1940 e 1950, observa-se, no Brasil, a expansão e a modernização significativa da rede hospitalar, que passa a demandar um maior número de enfermeiras diplomadas, favorecendo a consolidação desse campo profissional. Assim,

“(...) ao se transformarem gradativa mente as forças produtivas e as relações de produção aí dominantes, a enfermagem também se transforma. Mas o autêntico 'salto' representado pela sua profissionalização não significou uma ruptura total com o seu passado mesmo porque inexistem rupturas totais. Conseqüentemente, no ensino e na prática formal da enfermagem moderna brasileira subsistem traços, embora transfigurados, de sua prática e aprendizagem pre gressas (não apenas brasileira): a religiosidade transubstanciada em princípios éticos e deontológicos; a disciplina militar revivida nas escolas, onde se apregoam rígidas normas de conduta; o empirismo preservado no trabalho doexpressivo núme ro de atendentes de enfermagem que desempenham suas atividades sem ser recebido nenhum preparo formal" (Silva, 1989, p. 81). 
O impulso modernizador no Brasil, que se inicia no final da década de 1950, desencadeia, posteriormente, uma série de reformas no campo da saúde: a implementação das Ações Integradoras de Saúde - AIS (1973), a criação do Ministério da Previdência e Assistência Social (1974) e do Sistema Nacional de Saúde (1975), que separa as ações de saúde pública das ações ditas de atenção às pessoas, e o Instituto Nacional de Assistência Médica da Previdência Social - Inamps (1977), cuja implementação visava atender exclusivamente as pessoas com registro de trabalho em carteira, ficando para as secretarias estaduais de Saúde o atendimento dos demais segmentos da população (Pará, s/d).

$\mathrm{O}$ atendimento à saúde da população até os anos 80 foi marcado pelas seguintes características: compra de serviços de saúde da esfera pública pelo setor privado; assistência do setor público direcionada basicamente aos trabalhadores com vínculo empre gatício formal, gerando tratamento desigual à população; desperdício de re cursos e baixa qualidade dos serviços como conseqüências da atomização das ações de saúde entre os dive rsos seto res e instituições; oferta desigual dos serviços entre as regiões. Esses aspectos maximizaram a crise do setor além da insatisfação da população e dos profissionais, o que conduziu a movimentos e ações no sentido de neutralizar essa situação (Escoda e Lima, 1992).

Em 1978, é realizada a Reunião de Alma-Ata, na então União Soviética, colocando a saúde no centro do debate mundial. Assume-se como meta a "Saúde para todos", envolvendo prioritariamente a atenção primária à saúde. A declaração elaborada determina que esse compromisso deveria constituir-se medida urgente dos governantes, reconhecendo que a saúde é mais do que a ausência de doença. Ou seja, é direito de todos a promoção, prevenção e reabilitação no âmbito da saúde individual e coletiva. Exige-se, ainda, a participação da comunidade no planejamento, organização, funcion a mento e regulação da atenção primária à saúde, envolvendo recursos das diferentes esferas governamentais.

Quanto aos profissionais da saúde - enfermeiros, médicos e também parteiras e agentes comunitários —-, determina-se a necessidade de uma formação que valorize não apenas a dimensão técnica (conhecimento especializado), mas o social, reconhecendo a importância do trabalho em equipe e do atendimento de demandas da comunidade.

No Brasil, como em muitos países, a Declaração de Alma-Ata influencia a definição e implementação de políticas. Assim, com o processo da Reforma Sanitária Brasileira, cria-se, em 1986, o Sistema Unificado e Descentralizado de Saúde (Suds), preservando os princípios da co-gestão, descentralização e universalização da atenção à saúde (Pará, s/d).

Esses cenários de mudanças são fortalecidos com a promulgação da Constituição Federal em 1988, por estabelecer que "a saúde é direito de todos e dever do Estado" (artigo 186). Isso vem assegurar: 
“(...) o acesso universal e igualitário das ações e serviços de saúde, com regionalização e hierarqu i za ção, descentralização com direção única em cada esfera de governo, participação e atendimento integral, com prioridade as atividades preventivas, sem prejuízo dos serviços assistenciais. (...) São atribuições do SUS em seus três níveis de gover no, além de outras, ordenar a formação de rec u rsos humanos na área da saúde" (Brasil, 1988).

Entretanto, essas conquistas não garantem o atendimento a algumas demandas do setor de saúde, considerando que:

“(...) há um grave descompasso entre a necessidade e a oferta, qualidade e quantidade de profissionais para atuarem no âmbito do SUS. A evolução dos conhecimentos e a velocidade com que tem ocorrido, estão a demandar do ap a relho fo rmador de todos os níveis e profissões uma agilidade não existente. De outro lado, tem restado aos serviços de saúde realizar este papel de 'formador' e atualizador dos profissionais que necessita. Há um esgarçamento na relação entre os cidadãos que demandam os serviços de saúde, públicos e privados, e os profissionais. (Pára, s/d).

No âmbito desta breve retrospectiva, entendemos ser importante sinalizar que a Aben, durante décadas, mostrou-se submissa às políticas oficiais e aos interesses das indústrias multinacionais; ausente na condução de debates sobre o papel do profissional enfermeiro no contexto histórico-social vigente; afastada das formulações das políticas públicas de saúde e relativas aos trabalhadores da enfer magem, favorecendo a re p rodução e legitimação das decisões dos formuladores oficiais (Albuquerque e Pires, 2001).

Entretanto, no final da década de 1970, movimentos de oposição ao autoritarismo da Direção Nacional passam a reconhecer que a enfermagem deve "buscar, internamente, abrir fendas e inserir outra forma de entender sua prática" (Rodrigues, 2005, p. 86). Como resultado dessa inquietação, o XXXI Congresso Brasileiro de Enfermagem, realizado em 1979, configura-se como momento crucial na discussão sobre os desafios da enfermagem brasileira.

Os conflitos políticos abrem espaço para a consolidação do Movimento Participação, que em 1986 assume a direção da Aben e ganha força ao contestar a reconhecida "postura rígida, autoritária e elitista das representações da enfermagem que se agravava com o não encaminhamento dos interesses e das reivindicações da categoria" (Rodrigues, 2005, p. 87).

Há uma intensificação dos debates sobre a formação do enfermeiro, a partir do final da década de 1980. Neles, denunciam-se as indefinições profissionais, o ensino pulverizado e centrado no ambiente hospitalar, e a inadequada relação dos cursos de graduação com o mercado de trabalho e também com o perfil demográfico e epidemiológico do país. Uma das conquis- 
tas dessa luta é a portaria $n^{\circ} 1.721 / 1994$ do Ministério da Educação, que passa a orientar a formação do enfermeiro (Rodrigues, 2005).

Esse quadro complexo nos instiga a procurar compreender a organização e a dinâmica das instituições formadoras de profissionais da saúde. Assim, ap reender algumas tendências que se ex p ressam na educaçãosup erior do profissional enfermeiroe nos debates que se efetivam em torno desta questão implica necessariamente considerar os marcos da história do setor de saúde no país, sobretudo do século XX e deste início do século XXI.

Entre as relevantes mudanças nas políticas educacionais no país, nas últimas décadas, está a Constituição Federal (1988), que determina os direitos sociais à educação, à saúde, ao trabalho, ao lazer, à segurança, à proteção à maternidade, à infância e à assistência aos desamparados (artigo 6). Além disso, prescreve os princípios da universalidade e gratuidade para educação e da descentralização da gestão e financiamento do sistema educacional. E, entre outros aspectos, estabelece que é responsabilidade do Estado o processo de formação dos re cu rsoshumanos necessários para a implementação do SUS (artigo 200).

A regulamentação dos dispositivos constitucionais para a educação se explicita com a Nova Lei de Diretrizes e Bases da Educação Nacional (lei ${ }^{\circ}$ 9.394), sancionada em 20 de dezembro de 1996, após um longo período de intensos debates.

Nessa lei é indicada a forma de organização dos sistemas de ensino, que deve observar os princípios constitucionais. Em relação ao ensino superior, são estabelecidas as finalidades: estímulo à criação cultural e ao desenvolvimento do espírito científico e do pensamento reflexivo; formação de profissionais em dife rentes áreas do conhecimento capazes de participar no desenvolvimento da sociedade brasileira; incentivo ao trabalho de pesquisa científica, tendo em vista o desenvolvimento da ciência, da tecnologia, da criação e difusão cultural; promoção à divulgação científica; favorecimento ao desejo permanente de aperfeiçoamento cultural e profissional; estímulo ao conhecimento dos problemas do mundo; e promoção a atividades de extensão com a participação da população (artigo 43). Apresenta uma nova forma de organização, que, afora as modalidades de ensino existentes (graduação, pós-graduação lato e stricto sensu e extensão), cria o curso seqüencial (artigo 44).

Esta lei é um marco inicial da reforma educacional no país na década de 1990, na qual ganha centralidade a questão curricular. Ações se concret izam para definir o perfil de profissionais que se deseja formar. Com isso se dá encaminhamento à elaboração das diretrizes curriculares para a educação básica, ensino médio e cursos de graduação.

As instituições de ensino superior são convocadas pelo MEC (edital $\mathrm{n}^{\circ}$ 04/1997) a apresentar propostas de reformulação de seus currículos para a 
consolidação de diretrizes curriculares em todas as áreas do conhecimento pelas comissões de especialistas.

No caso da enfer magem, registra-se a presença fundamental de um ator coletivo, a Aben, que participou ativa mente de todo o processo de discussão e elaboração das diretrizes. Os Seminários Nacionais de Diretrizes para a Educação em Enfermagem (Senadens), coordenados e executados pela entidade desde 1994, passaram a se constituir fóruns de discussão sobre a educação em enfermagem nos seus três níveis: médio/profissional, graduação e pós-graduação (Rodrigues, 2005).

Com os Senadens, oportuniza-se mais um processo de busca de uma outra legislação de ensino que pudesse superar a vigente, com vista a colocar o SUS no centro da formação. Ressalta-se que esse novo profissional não pode mais ter sua formação alicerçada somente no modelo biomédico, mas, também, nos fundamentos da saúde pública/saúde coletiva e na perspectiva do trabalho multiprofissional, rompendo com uma formação frag mentada e voltada principalmente à doença.

Ap rovam-se, em 7 de novembro de 2001, pelo Conselho Nacional de Educação, as Diretrizes Curriculares Nacionais do Curso de Graduação de Enfermagem (MEC, 2001), definindo “os princípios, fundamentos, condições e procedimentos da formação do enfermeiro" (artigo 2). Estabelece-se, então, o perfil do formando, egresso/profissional, que deve ter "formação generalista, humanista, crítica ereflexiva" (artigo 30). Assim sendo, estabelecemse as competências e habilidades geraisrelativas a atenção à saúde, tomada de decisões, comunicação, liderança, administração e gerenciamento, e educação permanente (artigo 4).

São determinados, ainda, os conteúdos essenciais da formação, tendo em vista as necessidades sociais da saúde com ênfase no SUS e garantia à integralidade das ações do cuidar em enfermagem: Ciências Biológicas e da Saúde, Ciências Humanas e Sociais, Ciências da Enfermagem (fundamentos, assistência, administração e ensino) (artigos 5 e 6).

Tais metas têm ampliado o debate e o encaminhamento de ações que favoreçam a re-significação e o redesenho da formação profissional em enfe rmagem no país. Vejamos, portanto, o que nos revelam as produções científicas sobre essa questão. Afinal, são os atores sociais, envolvidos diretamente com os processos educativos formais e o atendimento à saúde, os interlocutores privilegiados para nos falar sobre esses aspectos.

\section{A trajetória metodológica}

Segundo Costa e Carvalho (2001), "todo conhecimento produzido necessita e deve ser transmitido a outras pessoas com o objetivo de levá-las a pensar 
e a perceber tanto as coisas familiares de modo dife rente, quanto obter novas informações".

Assim, realizar uma investigação de natureza exploratório-descritivae retrospectiva sobre a produção científica em determinado campo do saber, representa mais um canal de reflexão e socialização de importantes resultados de estudos desenvolvidos.

O projeto de pesquisa que ora desenvolvemos tem sua origem no Projeto Integrado Universitas, realizado por pesquisadores que integram o Grupo de Trabalho sobre Política do Ensino Superior da Associação Nacional de Pós-Graduação e Pesquisa em Educação (Anped). Os objetivos são sistematizar e analisar a produção científica sobre educação superior no Brasil desde 1968 e consolidar um banco de dados e uma biblioteca virtual2 2 .

No processo de ap roximação à produção científica sobre a formação do enfermeiro, um passo inicial foi o acesso ao Portal de Periódicos da Coord enação de Aperfeiçoamento de Pessoal de Nível Superior (Capes), atualmente o maior banco de dados virtual na área acadêmica da América Latina. Na relação de 129 periódicos na área da enfermagem, estão incluídos somente três nacionais. Entretanto, nesta primeira fase da pesquisa, optamos por trab alhar com os periódicos cujos textos completos estão disponibilizados on-line (Portal de Periódicos, 2005).

A Revista Latino-Americana de Enfermagem (Latin American Journal of Nursing), editada desde 1993, é uma publicação oficial da Faculdade de Enfermagem da Universidade de São Paulo em Ribeirão Preto (SP) e do Centro Colaborador da Organização Mundial da Saúde para o Desenvolvimento da Enfermagem e Obstetrícia e afiliada à Associação Brasileira de Editores Científi$\cos (\mathrm{Abec})$. Na classificação Qualis dos veículos editoriais de divulgação da produção intelectual de docentes e discentes dos programas de pós-graduação, realizada pela Capes, a esse periódico é atribuído o conceito Nacional B (Classificação Média).

A Reme - Revista Mineira de Enfermagem (Nursing Journal of Minas Gerais), publicada pela Escola de Enfermagem da Unive rsidade Federal de Minas Gerais (UFMG) desde 1997, também se enquadra como periódico Nacional B na classificação Qualis.

O período focalizado foi 2001 a 2005. Os textos foram selecionados pelas seguintes palavras-chave: enfermagem, formação, ensino, educação e, ainda, pela leitura do editorial e sumário de cada fascículo. Do total de 527 trabalhos identificados nesses periódicos, entre editoriais, artigos de pesquisa, artigos originais, revisões bibliográficas, relatos deexperiências, notas/informativos, selecionamos 51 textos, sendo 36 da Revista Latino-americana de Enfermagem e 15 da Reme ${ }^{3}$. Na Tabela 1, constam os resultados desse levantamento. 
Tabela 1

Distribuição comparativa da produção científica sobre formação do enfermeiro e outros temas, por ano de publicação, em dois periódicos científicos (2001-2005)

\begin{tabular}{|c|c|c|c|c|c|c|c|c|c|c|c|c|c|c|}
\hline \multirow[t]{3}{*}{ Periódicos } & \multicolumn{2}{|c|}{2001} & \multicolumn{2}{|c|}{2002} & \multicolumn{2}{|c|}{2003} & \multicolumn{2}{|c|}{2004} & \multicolumn{2}{|c|}{2005} & \multicolumn{4}{|c|}{ Total } \\
\hline & \multirow[t]{2}{*}{$\begin{array}{l}\text { Form. } \\
\text { do enf. }\end{array}$} & \multirow[t]{2}{*}{$\begin{array}{l}\text { Outros } \\
\text { temas }\end{array}$} & \multirow[t]{2}{*}{$\begin{array}{l}\text { Form. } \\
\text { do enf. }\end{array}$} & \multirow[t]{2}{*}{$\begin{array}{l}\text { Outros } \\
\text { temas }\end{array}$} & \multirow[t]{2}{*}{$\begin{array}{l}\text { Form. } \\
\text { do enf. }\end{array}$} & \multirow[t]{2}{*}{$\begin{array}{l}\text { Outros } \\
\text { temas }\end{array}$} & \multirow[t]{2}{*}{$\begin{array}{l}\text { Form. } \\
\text { do enf. }\end{array}$} & \multirow[t]{2}{*}{$\begin{array}{l}\text { Outros } \\
\text { temas }\end{array}$} & \multirow[t]{2}{*}{$\begin{array}{l}\text { Form. } \\
\text { do enf. }\end{array}$} & \multirow[t]{2}{*}{$\begin{array}{l}\text { Outros } \\
\text { temas }\end{array}$} & \multicolumn{2}{|c|}{$\begin{array}{l}\text { Form. } \\
\text { do enf. }\end{array}$} & \multicolumn{2}{|c|}{$\begin{array}{l}\text { Outros } \\
\text { temas }\end{array}$} \\
\hline & & & & & & & & & & & $n^{\circ}$ & $\%$ & $\mathrm{n}^{\circ}$ & $\%$ \\
\hline \multicolumn{15}{|l|}{ Revista } \\
\hline $\begin{array}{l}\text { Latino-Americana } \\
\text { de Enfermagem }\end{array}$ & 89 & 6 & 91 & 10 & 101 & 8 & 120 & 9 & 61 & 3 & 462 & 92,8 & 36 & 7,2 \\
\hline \multicolumn{15}{|l|}{ Revista Mineira } \\
\hline $\begin{array}{l}\text { de Enfermagem } \\
\text { (Reme) }\end{array}$ & 16 & 2 & 16 & 3 & 27 & 3 & 40 & 7 & - & - & 99 & 86,8 & 15 & 13,2 \\
\hline \multirow[t]{2}{*}{ Total } & 105 & 8 & 107 & 13 & 128 & 11 & 160 & 16 & 61 & 3 & \multicolumn{2}{|c|}{561} & \multicolumn{2}{|c|}{51} \\
\hline & 92,9 & 7,1 & 89,2 & 10,8 & 92,1 & 7,9 & 92 & 8 & 95,3 & 4,7 & \multicolumn{2}{|c|}{91,7} & \multicolumn{2}{|c|}{8,3} \\
\hline
\end{tabular}

Fonte: os autores, a partir do Portal de Periódicos/Capes

A análise do material selecionado compreendeu os seguintes procedimentos: leitura dos resumos, com vista a verificar se o tema central - formação do enfermeiro - é abordado; leitura dos textos completos selecionados para a identificação de núcleos temáticos; elaboração de síntese das informações por subcategorias temáticas, procurando evidenciar pontos-chave dos conhecimentos e reflexões construídas.

\section{Saberes construídos: uma aproximação preliminar}

O processo de ap roximação à produção científica em enfermagem re p resentou um desafio. Entretanto, o desafio maior foi a análise dos textos escolhidos, que nos encaminhou ao levanta mento de núcleos temáticos. Acreditamos que esses núcleos expressam, embora parcialmente, conhecimentos construídos sobre a formação do profissional enfermeiro: fundamentos pedag ógicos, ensino de enfermagem e currículo.

\section{Fundamentos pedagógicos}

Ao longo do período estudado, constatamos que reflexões, resultados de pesquisa, experiências e revisões bibliográficas têm como foco fundamentos que sustentam o modelo vigente da formação do enferme iro, e há também, aqueles que orientam trajetórias de transformações, tanto nos espaços de formação como nas práticas assistenciais desse profissional. 
Um conceito recor rente nos poucos trabalhos identificados nesta temática é a interdisciplinaridade. Nos textos, os autores procuram compreender desde a trajetória conceitual, explicitando o significado da interdisciplinaridade em uma perspectiva de superação do modelo 'disciplinar' dos saberes (paradigma cartesiano), até a comunicação de práticas educativas no âmbito da formação de nível s uperior, cuja orientação se realiza pela interação de saberes e atores sociais.

No âmbito da educação superior, a interdisciplinaridade é entendida como uma inter-relação e interação dos conhecimentos, potencializando as disciplinas pelo diálogo entre si e outras formas de conhecimento e metodologias, com a intencionalidade de construir um novo conhecimento. Assim, representa:

“(...) uma proposta de 'religare' entre o conhecimento científico e a complexidade do mundo vivido, para a medida do humano na produção da ciência, visando a superação da dicotomia entre teoria e prática. É uma das chaves para a compreensão do mundo, uma vez que esse não é feito de coisas isoladas, mas consiste de várias dimensões compleme $\mathrm{n}$ t a re s. (...) é u m conceito que se aplica às ciências, à produção do conhecimento e ao ensino, especialmente em áreas que demandam, de forma direta, a interdisciplinaridade, como, por exemplo, a saúde" (Vilela e Mendes, 2003).

Um outro fundamento que emerge nas produções é a educação reflexiva. Os autores que, direta ou indiretamente, tratam deste tema, procuram arg umentar que ele se constitui em premissa necessária para a formação do profissional enfermeiro.

São principalmente mencionados Lauren Stenhouse, Donald Schön e Paulo Fre ire, autores que, em seus estudos sobre a educação formal, focalizam essa questão. Alguns pontos discutidos, em re ferência a esses autore s, merecem destaque.

Em relação às idéias de Stenhouse, são indicados importantes estudos desenvolvidos na década de 1970, nos quais se defende a tese do professor como "produtor de conhecimentos sobre situações vividas em sua prática docente e não apenas como simples re produtor e executor de conhecime ntos previamente estabelecidos"' (Gomes e Casagrande, 2002).

Em relação aos pressupostos de Schön acerca do saber profissional, trab alhos salientam a premissa básica da "ação-reflexão-ação". Ou seja, o conhecimento-na-ação, a refl exão-na-ação e a refl exão sobre a reflexão-na-ação. Os autores do textos estudados defendem, portanto, que a formação profi issional do enfermeiro seja alicerçada nesses princípios, uma vez que

“(...) o diálogo entre o pro fessor e o aluno constitui princípio de procedimento que leva ao conhecimento crítico do ponto de vista educativo e que estabelece 
uma relação forte com o processo de levar a pensar, ao invés de apenas se preocupar com o resultado do processo" (Gomes e Casagrande, 2002).

Paulo Freire é referenciado para dar suporte às reflexões e análises relativas a reformas curriculares em realização, experiências com metodologias problematizadoras e estratégias de ensino centradas no aluno e em práticas profissionais, que têm surgido em alguns cursos de graduação de enfermagem no Brasil.

Os interlocutores das revistas reconhecem que é necessário romper com um processo educativo re vestido de autoritarismo, distanciado-se de uma prática de formação onde o educador é figura que centraliza todos os desejos, conhecimentos e possibilidades de ação. A partir da perspectiva de uma pedagogia crítica e construtiva, “a prática educativa faz-se pelo próprio aluno, de dentro para fora, e não de cima para baixo, como uma doação e imposição" (Godoy, 2002). Portanto, reforça-se que

“(...) a enfermeira, em sua prática assistencial mediatizada pelas idéias freirianas, pode se considerar, junto com o seu cliente, também um ap rendiz, no momento em que ela visualiza o cuidado também como atividade de Educação em Saúde, não se percebendo dona do cuidado, e não tendo uma atitude verticalizada no ato holístico de 'cuidar'. Assim, ela poderá construir uma prática libertadora, crítica, valorizando o cliente" (Miranda e Barroso, 2004).

Na análise dos textos, constatamos que as discussões dos fundamentos da formação do enfermeiro abrangem teorizações e reflexões, apresentando, de uma forma geral, premissas e posicionamentos consensuais. Explicitam-se idéias que sustentam a perspectiva crítico-reflexiva como alicerce indispensável às práticas educativa s. A multidimensionalidade destas práticas é reconhecida na medida em que a interdisciplinaridade é apresentada como suporte para as mudanças na enfermagem. Os autores dos textos pesquisados defendem a busca por outra lógica na relação aluno/professor/formação, implicando a superação da frag mentação e do reducionismo do conhecimento, da centralidade do professor nos processos de ensino-aprendizagem e do distanciamento entre as instituições formadoras e as demandas e necessidades das práticas assistenciais na saúde.

\section{Ensino de enfermagem}

As publicações em que se ab orda esta temática - o ensino de enfermagem - sinalizam caminhos rumo à integração entre os conhecimentos e as práticas assistenciais, tendo em vista o novo perfil profissional do enfermeiro.

É importante ressaltar que há um esforço significativo de estudiosos e estudiosas no sentido de socializarem experiências que têm sido decisivas 
na superação de uma pedagogia tradicional, dando lugar a estratégias que favo reçam a reconstrução de relações políticas, sociais e culturais em cenários de formação, mostrando que, ainda,

“(...) o ensino de enfermagem não só privilegia o estudo do corpo em sua dimensão biológica, como reforça a fragmentação do corpo. (...) há uma grande preocupação em oferecer muita informação, em detrimento da formação e do desenvolvimento das capacidades de trabalhar com essa informação.Finalmente, o ensino de graduação atual não dá ênfase à formação do ap rendiz autônomo que precisa conhecer sua maneira própria de aprender, para assumir a responsabilidade pela aprendizagem" (Stedile e Friendleer, 2003).

Entre os estudos que tratam de mudanças no ensino, destacam-se os cursos de enfermagem da Faculdade de Medicina de Marília (Fanema), da Unive rsidade Estadual de Londrina (UEL), da Universidade Federal de Goiás (UFGO), da Universidade Federal do Mato Grosso do Sul (UFMS), da Universidade de São Paulo em Ribeirão Preto e da UFMG.

Nesses estudos, enfatiza-se o emprego de procedimentos de ensinoaprendizagem que valorizam "a formação da competência humana, o processo do saber pensar, do ap render em um propósito ético político" (Stedile e Friendleer, 2003).

Os conhecimentos sistematizados em torno do ensino na enfermagem provêm, na maioria das vezes, de estudos sobre outras disciplinas. Apesar das especificidades dos conteúdos, as experiências relatadas compartilham pressupostos pedagógicos que colocam o aluno no centro do processo de ensino-aprendizagem, criando condições para que ele desenvolva autonomia pessoal e profissional bem como senso crítico ao enfrentar problemas e desafios que emergem no dia-a-dia do exercício profissional.

Os estudos valorizam o professor, demonstrando a necessidade de se superar o papel autoritário e de transmissor do saber, ganhando cada vez mais força a defesa de professores reflexivos.

“A atuação de docentes na enfermagem, numa perspectiva crítico-reflexiva, vem mobilizando algumas instituições de ensino, em especial de nível superior. O propósito é construir um modelo curricular, com um processo de formação articulado com o mundo do trabalho, que rompa com a dicotomia teoria e prática, com o uso de estratégias pedagógicas inova d or a s, com ensino contextualizado,proporcionado aprendizagem significativa e um futuro profissional mais crítico e compromissado com ensino contextualizado, proporcionando aprendizagem significativa e um futuro profissional mais crítico e compromissado com as questões profissionais e sociais" (Faria e Casagrande, 2004). 
Nos textos examinados, ficam evidentes algumas características que devem configurar o processo de ensino-aprendizagem do enfermeiro, a saber: - o aluno deve se responsabilizar pelo percurso de sua aprendizagem, assumindo o papel de sujeito emancipado na construção de sua própria formação; - o professor deve atuar como mediador nesse processo, procurando oferecer as condições (estratégias e recursos) de aprendizagem provenientes de si mesmo, de suas próprias experiências e de experiências com a comunidade;

- valorização de metodologias com enfoque problematizador (por exemplo, metodologia da problematização, aprendizagem baseada em problemas) visando ao desenvolvimento de competências de um enfermeiro crítico-reflexivo;

- o uso de metodologias que maximizem a integração teoria e prática e temáticas emergentes das situações vivenciadas no trabalho, pro movendo a análise e reflexão sobre a enfermagem, a re-significação e re-criação do modo de cuidar;

- adoção de estratégias que priorizem as relações interpessoais e o cre s c imento pessoal;

- incentivo contínuo ao pro fessor e ao aluno a pensarem sobre seus 'fa zeres' e 'experiências', no sentido de compreender seus significados no contexto da formação e no futuro exercício profissional; e

- garantia da ação-reflexão-ação nos espaços de ensino-aprendizagem, incentivando ao aluno ex pressar seus sentimentos e dúvidas com liberdade em um clima de afetividade e troca entre os envolvidos no processo.

Em síntese:

\begin{abstract}
"O ensino deve buscar relacionar o conhecimento teórico às experiências vivenciadas pelo exercício da reflexão, entendimento, descoberta e imaginação, os quais são enriquecidos pelos trabalhos literários, culminando no desenvolvimento e entrelaçamento do pensar, conhecer e escre ver num esforço para entender o vivido nas escolas e nos encontros com os pacientes" (Pe reira apud Camacho e Espírito Santo, 2001).
\end{abstract}

Nos trabalhos em que identificamos o ensino de enfermagem como objeto de estudo, observa-se principalmente a preocupação em considerar as novas exigências para a formação do profissional em enfermagem, tendo o SUS como fio condutor. Coloca-se em destaque a premissa de que os cenários de aprendizagem devem favorecer a integração dos saberes às práticas profissionais. Torna-se, então, essencial trabalhar os diversos aspectos que configuram essa realidade, onde alunos e professores passam a ser co-construtores dos conhecimentos e de possíveis redesenhos de práticas educativas e assistenciais. 


\section{Currículo}

Nesse núcleo temático, identificamos, principalmente, trabalhos sobre mudanças que vêm sendo realizadas em alguns cursos de graduação de enfermagem no país. As discussões têm, como ponto de partida, apontamentos sobre os pressupostos que marcam a formação do enfermeiro a partir de 1923, quando se cria a primeira escola de enfermagem no Brasil.

Nores gate da história de alguns cursos de enfermagem, são indicados aspectos que caracterizam a trajetória de formação do enfermeiro, nitidamente atrelada a momentos e movimentos das ciências da saúde e do setor de saúde no país.

Ao tratarem dos desafios atuais das instituições de ensino, as publicações analisadas apresentam argumentações quanto à necessidade de se repensar a formação do enfermeiro tendo em vista a regulamentação atual da profissão, as diretrizes educacionais, as políticas públicas do setor saúde e os cenários de atuação profissional.

Alguns estudos registram também um tímido processo de superação do modelo tradicional de formação. Apesar de esforços para se consolidar mudanças necessárias, constata-se a insuficiência de bases teóricas para sustentar as novas situações educativas norteadas pelos princípios do currículo integrado; a inexperiência docente em relação aos processos didáticos inova dores; e, ainda, o predomínio da dimensão cognitiva no processo de ensinar-aprender (Laluna e Ferraz, 2003).

No âmbito dos conhecimentos produzidos sobre a formação do enfermeiro, ganha importante espaço o Projeto Político Pedagógico. Defende-se o compromisso de se propor a construção de

“(...) um processo de formação articulado ao mundo do trabalho, rompendo com a separação entre teoria/prática, utilizando metodologia ativa de ensino-aprendizagem, pro p o rcionandoap ren dizagem significativa. Isso determina a possibilidade de mudanças nos diversos sujeitos envolvidos no processo em questão, tendo como perspectiva a formação de profissional crítico, reflexivo, compromissado com seu papel social, sendo um sujeito ativo no seu próprio percurso de vida e de trabalho, contribuindo para a construção de um sistema de saúde pautado nos princípios do Sistema Único de Saúde - SUS" (Chirelli e Mishima, 2003).

Ao lado disso, salienta-se que:

“(...) o projeto pedagógico tem conotação política, pois reconhecemos que está inserido num determinado contexto dinâmico, construído historicamente pelos sujeitos que atuam no cotidiano da escola por meio de práticas pedagógicas com as mais dive rsas visões de mundo, permeadas por ideologias, culturas, subjetivi- 
dades, criando tensão entre as mesmas, sendo uma arena de conflitos e interesses, estando essas práticas explícitas ou veladas nas contradições do processo em si" (Chirelli e Mishima, 2003).

Nas análises sobre avanços pedagógicos e político-sociais nos cursos de enfermagem, reafirma-se a relevância do papel do professor no processo de formação do enfermeiro. E, por conseguinte,

“(...) a necessidade de capacitação docente como estratégia para uma reconstrução curricular que atenda ao projeto político pedagógico que se efeti venas salas de aula e nos cenários de prática. Enfatizamos, ainda, que uma mudança curricular satisfatória depende do desenvolvimento das capacidades de auto-análise e reflexão dos professores e que a capacitação docente, ao lado da reflexão sobre a prática educativa-progressista deve levar a uma pedagogia fundamentada na ética, no respeito à dignidade e à própria autonomia do educando" (Chianca et al., 2004).

Ao focalizaremas Diretrizes Curriculares Nacionais dos Cursos de Graduação em Enfermagem, aprovada em 2001, os autores apontam que:

“(...) o perfil do formando/egresso profissional, competências e habilidades gerais e específicas, conteúdos curriculares, estratégias e atividades complementares, organização, acompanhamento e avaliação do curso. (...) deve ser capacitado a atuar, com senso de responsabilidade social e compromisso com a cidadania, como promotor da saúde integral do ser humano" (Chianca et al., 2004).

Em relação a esse aspecto, nos inúme ros trabalhos publicados, subentende-se a premissa de articular os currículos de enfermagem e o SUS. E explicita-se que os conteúdos essenciais

“(...) devem estar relacionados com todo o processo saúde-doença do cidadão, da família e da comunidade, integrado à realidade epidemiológica e profissional, proporcionando a integralidade das ações do cuidar em enfermagem, devendo contemplar as ciências biológicas e da saúde, ciências humanas e sociais, ciências da enfermagem, fundamentos, assistência e administração" (Chianca et al., 2004).

Além disso, destaca-se que:

"As diretrizes curriculares constituem um conjunto de indicações que devem direcionar o processo educacional do ensino superior, orientando o planejamento acadêmico dos cursos de gra dua ção. Caracterizam-se pela flexibilidade, buscando romper com o modelo arcaico e rígido de ensino, trazendo o projeto pedagógico como base de gestão acadêmico-administrativo de cada curso e fornecendo os 
elementos das bases filosóficas, conceituais, políticas e metodológicas que definem as competências e habilidade essenciais à formação dos profissionais da saúde. (...) estão orientadas para contribuir no processo de construção do Sistema Único de Saúde (SUS), o que vem ao encontro da Constituição Federal que indica o papel relevante do SUS no delineamento de diretrizes para formação de re cu rsos humanos em saúde" (Clapis et al., 2004).

Ao longo da análise dos textos sobre currículo, pudemos verificar a necessidade de mudanças estratégicas nos processos e cenários de formação do enfermeiro. Depreende-se a importância de projetar essa formação num desenho curricular que inclua os espaços de produção das ações da saúde. Portanto, pensar no avanço qualitativo da enfermagem significa buscar novos caminhos que incorporem a reflexão da prática, sobre a prática e na prática, além de favorecer uma atuação mais humanizada e cidadã no ato de cuidar.

\section{Palav ras finais}

No exame das publicações, escolhas foram feitas a partir de critérios estabelecidos - desde o levantamento dos periódicos, da ap reensão dos núcleos temáticos, ao destaque de citações que representam tendências dos conhecimentos construídos sobre a formação do enfermeiro. Estes procedimentos nos permitiram verificar, no conjunto dos documentos, uma articulação com aspectos relacionados às recentes políticas públicas para o SUS e a educação (Lei de Diretrizes e Bases da Educação Nacional, de 1996, e Diretrizes Curriculares Nacionais para o Curso de Graduação em Enfermagem, de 2001).

Ainda que esta pesquisa tenha examinado somente textos veiculados em dois periódicos científicos da enfermagem, uma ap roximação preliminar a esse material nos autoriza considerar que os conhecimentos produzidos, cujos 'frag mentos' são aqui ap resentados, constituem concretas contribuições para a compreensão da formação do enferme i roe, conseqüentemente, para se repensar o currículo, consolidar um novo perfil profissional, avaliar e redirecionar o papel das instituições formadoras. A palavra de ordem é 'transformação'. E, nesse sentido, o apelo feito pelos estudiosos tem por base experiências concretas que indicam caminhos possíveis para mudanças.

A despeito do valor da produção científica estudada, podemos constatar que ela precisa ser intensificada, envolvendo tanto discussões sobre idéias, conceitos, teorias, como também o compartilhamento de experiências, que têm sido desenvolvidas em cursos de enfermagem no país.

Nesse sentido, cabe-nos reconhecer que: 
"O conhecimento do conhecimento obriga. Obriga-nos a assumir uma atitude de permanente vigília contra a tentação da certeza, a reconhecer que nossas certezas não são provas da verdade, como se o mundo que cada um vê fosse o mundo e não um mundo que construímos juntamente com os outros. Ele nos obriga, porque ao saber que sabemos não podemos negar que sab e mos. (...) Não é o conhecimento, mas sim o conhecimento do conhecime n t o, que cria o compro me t i mento" (Maturana e Varela, 2004, p. 267 e 268, grifos do autor).

Portanto, fica o convite aos leitores para ampliarem a análise ap resentada neste artigo e se aventurarem pela busca de respostas a inquietações que emergem do cotidiano acadêmico e dos próprios saberes construídos.

\section{Notas}

1 Professora do Programa de Pós-Graduação em Ensino em Ciências da Saúde da Universidade Federal de São Paulo (Unifesp) e do Programa de Estudos Pós-Graduados em Economia Política da Pontifícia Unive rsidade Católica de São Paulo (PUC-SP). Doutora em Psicologia da Educação pela PUC-SP. <oseiffe@attglobal.net>

2 O Banco de Bados Universitas pode ser acessado no endereço <www.pucrs.br/faced/ pos/universitas $>$.

3 Consideramos nesta pesquisa os textos publicados na Revista Mineira de Enfermagem (Reme) e na Revista Latino-Americana de Enfermagem, entre 2001 e 2005. Como, no mo mento da conclusão deste artigo, a Reme disponibilizava em seu site apenas os conteúdos dos núme ros publicados até julho/setembro de 2004 (volume 8, núme ro 3), analisamos somente o material anterior a esta data. Da Revista Latino-Americana de Enfermagem foram avaliados os conteúdos publicados até maio/julho de 2005 (volume 13, número 3). 


\section{Referências}

ALBUQUERQUE, Gelson L. de; PIRES, Denise Elvira. 2001. O Movimento Pa rticipação (MP): uma contribuição à história da enfermagem brasileira. Revista Brasileira de Enfermagem, v. 54, n. 2, p. 174-184.

BARREIRA, Ieda de A.; SAUTHIER, Ju ssara; BAPTISTA, Suely de S. 2001. O movi mento associativo das enfermeiras diplomadas brasileiras na primeira metade do século 20. Revista Brasileira de Enfermagem, v. 53, n. 4, p. 157-173.

BRASIL. 1988. Constituição da República Federativa do Brasil.

1996. Lei no. 9.394, de 20 de dezemb rode 1996. Estabelece as Diretrizes e Bases da Educação nacional.

CAMACHO, Alessandra Conceição L. F.; ESPIRITO SANTO, Fátima Helena do. 2001. Reflecting on nu rsing care and teaching. Revista Latino-Americana de Enfermagem, v. 9, n. 1. Disponível em: <www.scielo.br/scielo.php?script =2005 > . Acesso em: 26 abr. 2005.

CATANI, Afrânio M.; OLIVEIRA, João F. de; DOURADO, Luiz F. 2001. Educational politics, changes in the wo rk world and grade courses curriculum reformation in Brazil. Educação \& Sociedade, v. 22, n. 75, p. 67-83.

CHIANCA, Tânia C. M. et al. 2004. Repensando a realidade pedagógica na Escola de Enfermagem da Universidade Federal de Minas Gerais. Revista Mineira de Enfermagem, v. 8, n. 1. Disponível em: <www.enfermagem.ufmg. $\mathrm{br} / \mathrm{re} \mathrm{me} / \mathrm{REMEV} 8 \mathrm{N1}$.PDF $>$. Acesso em: 26 abr. 2005.

CHIRELLI, Mara Q.; MISHIMA, Silvana M. 2003. Critical reflexi ve education of nu rses from the nu rsing undergraduate program offe red by the School of Medicine of Marília (Famema). $R e$ vista Latino-Americana de Enfermagem, v. 11, n. 5. Disponível em: <www. scielo.br/scielo.php?script=sci_arttext \&pid=S0104-11692003000500003> . Acesso em: 2 mar. 2005.
CLAPIS, Maria José et al. 2004. Undergraduate education at the University of São Paulo at Ribeirão Preto College of Nursing throughout the 50 years of its history (1953-2003). Revista Latino-Americana de Enfermagem, v. 12, n. 1. Disponível em: <www.scielo.br/ scielo.php?script $=$ sci_arttext\&pid $=\mathrm{S}$ 0104-11692004000100002\&lng =en \& nrm=iso $>$. Acesso em: 2 mar. 2005.

COSTA, Roberta dos S.; CARVALHO, Daclé Vilma. 2001. Analysis of the scientific production by nu rses from $\mathrm{Mi}$ nas Gerais published in nursing journals. Revista Latino-Americana de Enfermagem, v. 9, n. 5. Disponível em: $<$ www.scielo.br/scielo.php?script=sci _arttext\&pid=S0104-1169200100050 $0004 \& \operatorname{lng}=$ en $\&$ nrm $=$ iso $>$. Acesso em: 2 mar. 2005.

ESCODA, Maria do Socorro Q.; LIMA, Maria de Fátima. 1992. Saúde, sociedade e governo. Texto apresentado às etapas municipais e estadual (RN), da IX Conferência Nacional de Saúde. Disponível em: <www.ufrnet.br/ scorpius/ 31-Saude-soc \% 20e\%20gov.htm $>$. Acesso em: 17 maio 2005.

FARIA, Josimerci I. L.; CASAGRANDE, Lisete D. R. 2004. Education for the XXI century and the reflexive teacher's formation in nursing. Revista LatinoA me ricana de Enfermagem, v. 12, n. 5. Disponívd em: <www.scielo.br/ scielo.php?script $=$ sci_arttext\& pid $=$ S0104-11692004000500017\&lng=en\& nrm=iso $>$. Acesso em: 2 mar. 2005.

FREIRE, Paulo. 1979. Ação cultural para a liberdade. $4^{\mathrm{a}}$ ed. Rio de Janeiro: Paz e Terra.

GODOY, Christine B. de. 2002. The nursing program of the State University of Londrina in the construction of a new educational proposal. Revista Latino-Americana de Enfermagem, v. 10, n. 4. Disponível em: <www.scielo.br/ scielo.php?script $=$ sci_arttext\& pid $=$ S0104-11692002000400018\&lng =en\& nrm=iso >. Acesso em: 2 mar. 2005. 
GOMES, Jomara B.; CASAGRANDE, Lisete D. R. 2002. Reflexive education in post-modernity: a bibliographical review. Revista Latino-Americana de Enfermagem, v. 10, n. 5. Disponível em: <www.scielo.br/scielo.php?script =sci_arttext\&pid=S0104-116920020 $00500011 \& \operatorname{lng}=$ en\&nrm $=$ iso\&tlng $=$ pt>. Acesso em: 2 mar. 2005.

LALUNA, Maria Cristina M. C.; FERRAZ, Clarice Aparecida. 2003. Understanding the theoretical bases of participative planning in the integrated curriculum of a nursing course. Revista Latino-Americana de Enfermagem, v. 11, n. 6. Disponível em: <www.scielo.br/ scielo.php?script $=$ sci_arttext $\&$ pid $=$ S0104-11692003000600011\&lng=en\& $\mathrm{nrm}=$ iso $>$. Acesso em: 2 mar. 2005.

LÚCIO, Clemente G.; SOCHACZEWSKI, Suzanna. 1998. Experiência de elaboração negociada de uma política de formação profissional. Educação \& Sociedade, v. 19, n. 64, p. 104-129.

MARZIALE, Maria Helena P. 2004. The internationalization of scientific production: a great challenge for Brazilian nursing. Revista Latino-Americana de Enfermagem, v. 12, n. 5. Disponível em: <www.scielo.br/scielo.php? script $=$ sci_arttext\&pid $=$ S0104-11692 $004000500001 \& \operatorname{lng}=\mathrm{en} \& \mathrm{nrm}=\mathrm{iso}>$. Acesso em: 2 mar. 2005.

MATURANA, Humberto R.; VARELA, Francisco J. 2004. A árvore do conhecimento: as bases biológicas da compreensão humana. $4^{\mathrm{a}}$ ed. São Paulo: Palas Athena.

MEC (Ministério da Educação). 2001. Resolução no. 3, de 7 de novembro de 2001. Institui Diretrizes Curriculares Nacionais do Curso de Graduação em Enfermagem.

MIRANDA, Karla C. L.; BARROSO, Maria Grasiela T. 2004. Freire's contribution to the practice and critical education in nursing. Revista Latino-Americana de Enfermagem, v. 12, n. 4. Disponível em: <www.scielo.br/scielo.php?script =sci_arttext\&pid=S0104-11692004000 $400008 \& \operatorname{lng}=$ en $\& n r m=$ iso \&tlng $=p t>$. Acesso em: 2 mar. 2005.
PORTAL DE PERIÓDICOS: base de dados. 2005. Brasília: Coordenação de Aperfeiçoamento de Pessoal de Nível Superior (Capes), 2000- . Disponível em: $<$ www.periodicos.capes.gov.br $>$. Acesso em: 8 set. 2005.

RODRIGUES, Rosa Maria. 2005. Diretrizes curriculares para a graduação em enfermagem no Brasil: contex to, conteúdo e possibilidades para a formação. Tese de Doutorado, Campinas: Faculdade de Educação, Universidade Estadual de Campinas.

SILVA, Graciette B. da. 1989. Enfermagem profissional: análise crítica. São Paulo: Cortez.

STEDILE, Nilva Lúcia R.; FRIENDLEER, Maria R. 2003. Metacognition and nu rsing teaching: a possible combination? Revista Latino-Americana de Enfermagem, v. 11, n. 6. Disponível em: <www.scielo.br/scielo.php?script =sci_arttext\&pid $=$ S0104-1169200300 $0600014 \& \operatorname{lng}=\mathrm{en} \& \mathrm{nrm}=\mathrm{iso}>$. Acesso em: 2 mar. 2005.

PARÁ. Secretaria Estadual de Saúde Pública do Pará. s/d. SUS: Sistema Único de Saúde. Disponível em: <www.sespa. pa.gov.br/SUS/sus/sus_oquee.htm $>$. Acesso em: 17 maio. 2005.

VILELA, Elaine M.; MENDES, Iranilde José M. 2003. Interdisciplinarity and health: bibliographic study. Revista Latino-Americana de Enfermagem, v. 11, n. 4. Disponível em: <www.scielo.br/ scielo.php?script $=$ sci_arttext $\&$ pid $=S$ 0104-11692003000400016\&lng $=$ en $\&$ nrm=iso $>$. Acesso em: 2 mar. 2005.

WHO (World Health Organization). 1978. Declaração de Alma-Ata. Conferência Internacional sobre Cuidados Primários em Saúde. Disponível em: <www. opas.org.br/coletiva/uploadArq/AlmaAta.pdf > . Acesso em: 17 maio. 2005.

Z AMBONI, Lílian Márcia S. 2001. Cientistas, jornalistas e a divulgação cientifica:subjetividade e heterogeneidade no discurso da divulgação científica. Campinas: Autores Associados.

Recebido em 30/07/2003

Aprovado em 13/07/2004 